\title{
ANALISA KEAUSAN KAMPAS REM PADA DISC BRAKE DENGAN VARIASI MATERIAL KAMPAS REM
}

\author{
Asri*dan Darmanto \\ *Jurusan Teknik Mesin, Fakultas Teknik, Universitas Wahid Hasyim \\ Jl. Menoreh Tengah X/22, Sampangan, Semarang 50236 \\ Jurusan Teknik Mesin Fakultas Teknik Unwahas \\ *Email: asrimawon@gmail.com
}

\begin{abstract}
Abstrak
Kampas rem merupakan salah satu komponen kendaraan bermotor yang berfungsi untuk memperlambat atau menghentikan laju kendaraan khususnya kendaraan darat. Gesekan yang terjadi antara material kampas dan disc brake mengakibatkan keausan. Alat uji keuasan kampas rem adalah alat uji yang digunakan untuk mengetahui laju keausan dan prediksi umur pakai material kampas rem. penelitian kali ini bertujuan untuk mengetahui nilai laju keuasan, volume yang hilang, koefisien keausan yang terjadi pada material kampas dan prediksi umur pakai material kampas rem. Analisa perhitungan menggunakan persamaan laju keausan dan menggunakan metode penurunan Archard (1953). Hasil perhitungan dengan menggunakan persamaan nilai laju keausan dan menggunakan metode penurunan Archard (1953) menunjukkan bahwa nilai kekerasan suatu material kampas berpengaruh terhadap nilai laju keausan, volume yang hilang, koefisien keausan dan umur pakai material kampas. Semakin besar nilai kekerasan suatu material kampas semakin besar pula nilai laju keausan, volume yang hilang, koefisien keausan yang terjadi pada material kampas dan umur pakai material kampas cenderung lebih cepat habis. Nilai laju keuasan tertinggi pada kampas yang mengandung material asbestos (material III) dan prediksi umur pakai material kampas paling panjang adalah kampas yang mengandung material non-asbestos (material II).
\end{abstract}

Kata kunci: kampas, disc brake, keausan, asbestos, non-asbestos

\section{PENDAHULUAN}

Rem merupakan salah satu komponen pada kendaraan yang harus ada dan bekerja dengan baik karena menyangkut keselamatan pengendara dan orang lain. Salah satu bagian terpenting dalam sistem pengereman adalah kampas rem. Kampas rem merupakan salah satu komponen kendaraan bermotor yang berfungsi untuk memperlambat atau menghentikan laju kendaraan khususnya kendaraan darat. Untuk mendapatkan pengereman yang maksimal maka dibutuhkan kampas rem dengan kemampuan pengereman yang baik.

Keausan (wear) adalah hilangnya materi dari permukaan benda padat sebagai akibat dari gerakan mekanik. Pengujian keausan dapat dilakukan dengan berbagai macam metode dan teknik, yang semuanya bertujuan untuk mensimulasikan kondisi keausan aktual. Salah satunya adalah alat uji keausan kampas rem dimana kampas diam dan mendapat tekanan beban pengeraman dalam disc brake yang berputar.

Penelitian keausan telah dilakukan oleh sukamto (2012) tentang keausan kampas rem dengan membandingkan merk kampas yang beredar dipasaran.
Syahid Khadir Ali Maulana dkk (2015) telah melakukan percobaan dengan menggunakan material asbsestos dan non asbestos dengan variasi beban pengereman 2 $\mathrm{kg}, 3 \mathrm{~kg}$, dan $4 \mathrm{~kg}$ dalam kondisi basah dan kering.

Laju keausan yang terjadi pada material dicari menggunakan persamaan sukamto (2012).

$$
N=\frac{W 0-W 1}{A \cdot t}
$$

Volume yang hilang dapat dicari menggunakan persamaan (3) dengan terlebih dahulu mencari massa jenis material dengan menggunakan pesamaan (2)

$$
\begin{aligned}
& \rho \text { material }=\frac{\text { massa }(\text { gram })}{V \text { material }\left(\mathrm{mm}^{3}\right)}(2) \\
& V \text { yang hilang }=\frac{\text { massa }(\mathrm{gram})}{\rho\left(\frac{\mathrm{gram}}{\mathrm{mm}^{3}}\right)}(3)
\end{aligned}
$$

Koefisien keausan dicari menggunakan metode arcard pada persamaan (6) dengan mencari jarak yang ditempuh terlebih dahulu menggunakan persamaan (5). 


$$
\begin{gathered}
\mathrm{SA}=\mathrm{n}(\text { menit }) \cdot \mathrm{t}(\mathrm{menit}) \cdot 2 \cdot \pi \cdot \mathrm{r}(\mathrm{mm}) \\
\mathrm{V}=\mathrm{FN}(\mathrm{N}) \cdot \mathrm{Kd}\left(\mathrm{mm}^{3} / \mathrm{mm}\right) \cdot \mathrm{S}(\mathrm{mm}) \\
\mathrm{Kd}=\frac{\mathrm{V}\left(\mathrm{mm}^{3}\right)}{\mathrm{FN}(\mathrm{N}) \cdot \mathrm{S}(\mathrm{mm})}
\end{gathered}
$$

Untuk memprediksi umur kampas persamaan (7)

$$
\mathrm{t}=\frac{\mathrm{S}(\mathrm{mm})}{\mathrm{n}(\mathrm{menit}) \cdot 2 \cdot \pi \cdot \mathrm{r}(\mathrm{mm})}
$$

\section{METODE PENELITIAN}

Pengujian keausan kampas rem pada disc brake menggunakan alat ujia keausan dengan gaya pengereman $166,77 \mathrm{~N}$ dan putaran pada disc 735.1 RPM. Urutan penelitian seperti ditunjukan Gambar 1.

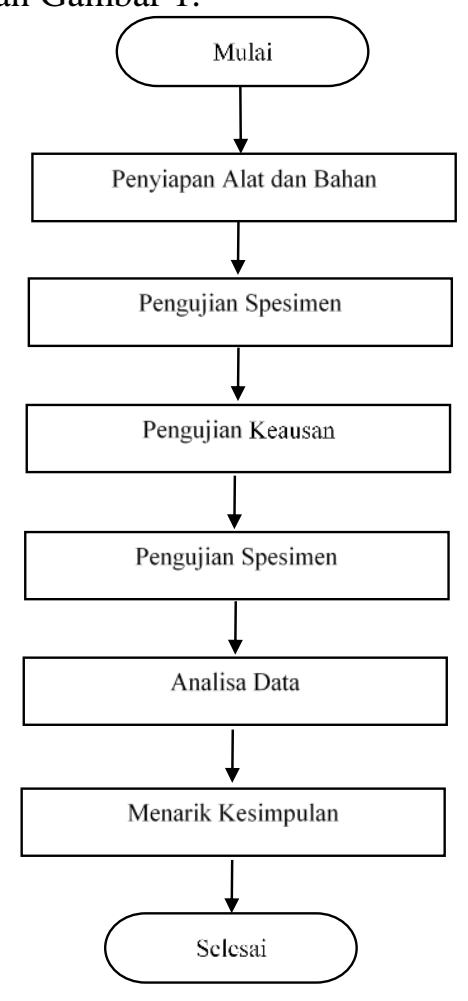

Gambar 1. Alur Penelitian

\section{Alat dan Bahan}

Pada penelitian ini menggunakan alat dan bahan sebagai berikut:

1. Bahan material yang digunakan

Bahan yang digunakan pada penelitian kali ini adalah kampas rem depan dengan penyusun material I dan II mengandung material non-asbestos dan metrial III mengandung material asbestos seperti pada Gambar 2 dan Tabel 1.

\section{Gambar 2 Bahan yang digunakan}

Tabel 1. Bahan yang digunakan

\begin{tabular}{|c|c|c|c|c|}
\hline \multirow{2}{*}{ Bahan } & \multicolumn{2}{|c|}{ Kekasaran $(\mu \mathrm{m})$} & \multicolumn{2}{c|}{ Kekerasan (HRC) } \\
\cline { 2 - 5 } & Sisi A & Sisi B & Sisi A & Sisi B \\
\hline Material I & 1.79 & 1.65 & 26.2 & 32.3 \\
\hline Material II & 1.86 & 1.97 & 29.3 & 37.1 \\
\hline Material III & 2.87 & 2.9 & 49 & 54 \\
\hline
\end{tabular}

2. Alat Uji keausan

Untuk menguji keausan yang terjadi pada kampas rem menggunakan alat uji keausan seperti pada gambar 2 .

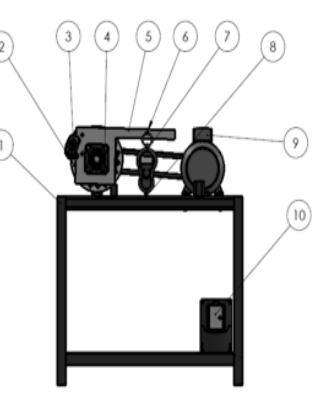

(a)

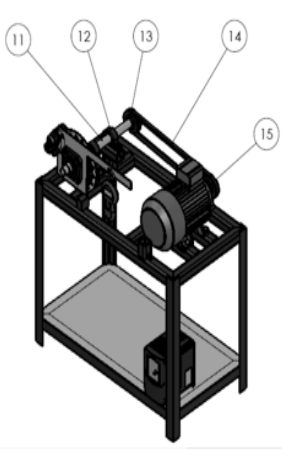

(b)
Gambar 3 Alat Uji Keausan (a) tampak depan (b) tampak isometric

Tabel 2 Bagian-bagian Alat uji keausan

\begin{tabular}{lll}
\hline No & Nama & Kegunaan \\
\hline 1 & Rangka & Tempat alat \\
2 & Calliper brake & Alat untuk pengereman \\
3 & Disc & Piringan untuk uji keausan \\
4 & Pillow block & Tempat bearing \\
5 & Plat ayunan & $\begin{array}{l}\text { Penghubung antara caliper brake dengan } \\
\text { timbangan }\end{array}$ \\
\hline 6 & Pin pengait & Pengait antara plat ayunan dan \\
& & timbangan ayunan \\
7 & Timbangan digital & Mengetahui beban \\
8 & Pengait rangka & Mengaitkan timbangan pada rangka \\
9 & Motor & Penggerak \\
10 & Inventer & Pengatur kecepatan \\
\hline 11 & poros & Penghubung antara pillow block dengan \\
& & pully poros \\
12 & Pillow block & Bantalan \\
13 & Pully poros & Penggerak pillow block \\
14 & Sabuk & Transmisi daya \\
15 & Pully motor & Pengerak transmisi \\
\hline & & \\
\end{tabular}




\section{HASIL DAN PEMBAHASAN}

Pengujian kampas rem dengan menggunkan alat uji keausan, didapat hasil pengujian sebagai berikut:

\section{Laju keausan}

Persamaan (1) Sukamto (2012) untuk mencari laju keausan yang terjadi pada material. Laju keausan hasil eksperimen dapat dilihat pada Tabel 3 .

Tabel 3. Laju keausan

\begin{tabular}{ccccccc}
\hline Waktu & \multicolumn{5}{c}{ Laju Keausan (gram/mm ${ }^{2}$.detik) } \\
\cline { 2 - 7 } (detik) & Mat IA & Mat IB & Mat IIA & Mat IIB & Ma IIIA & Mat IIIB \\
\hline 300 & $4,84.10^{-8}$ & $4,84.10^{-8}$ & $2,78.10^{-8}$ & $2,78.10-8$ & $2,30.10^{-8}$ & $2,30.10^{-8}$ \\
900 & $4,84.10^{-8}$ & $3,23.10^{-8}$ & $2,78.10^{-8}$ & $2,78.10^{-8}$ & $2,30.10^{-8}$ & $3,07.10^{-8}$ \\
1500 & $4,35.10^{-8}$ & $2,42.10^{-8}$ & $2,78.10^{-8}$ & $2,78.10^{-8}$ & $3,22.10^{-8}$ & $3,68.10^{-8}$ \\
2100 & $4,15.10^{-8}$ & $2,42.10^{-8}$ & $2,78.10^{-8}$ & $3,19.10^{-8}$ & $3,29.10^{-8}$ & $3,94.10^{-8}$ \\
\hline
\end{tabular}

Dari tabel 3 bisa disajikan menjadi grafik perbandingan laju keausan yang terjadi antar material yang bisa dilihat pada gambar 4 .

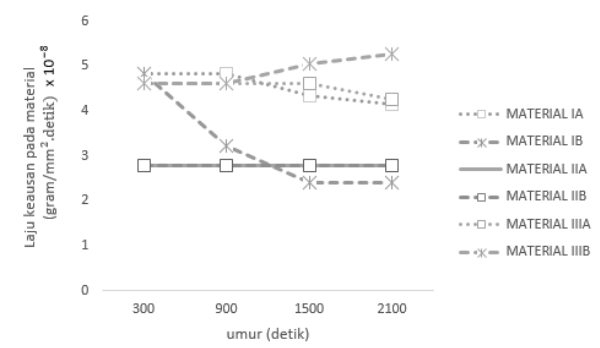

Gambar 4 Grafik perbandingan laju keausan yang terjadi antar material.

Dari gambar 4 dapat dilihat bahwa laju keausan yang terjadi pada tiap material bebeda. Semakin lama waktu yang ditempuh nilai laju keausan cenderung stabil dan mengalami penurunan.

\section{Volume yang Hilang}

Volume yang hilang dapat dicari menggunakan persamaan (3) dan hasil dari eksperimen dapat dilihat pada Tabel 4.

Tabel 4. Volume yang Hilang

\begin{tabular}{ccccccc}
\hline Waktu & \multicolumn{5}{c}{ Volume yang hilang $\left(\mathrm{mm}^{3}\right)$} \\
\cline { 2 - 7 } (detik) & Mat IA & Mat IB & Mat IIA & Mat IIB & Mat IIIA & Mat IIIB \\
300 & 7,71 & 6,25 & 4,97 & 5,12 & 4,66 & 4,58 \\
900 & 23,12 & 12,49 & 14,90 & 15,34 & 13,98 & 18,33 \\
1500 & 34,68 & 15,62 & 24,84 & 25,58 & 32,62 & 36,64 \\
2100 & 46,24 & 21,86 & 34,77 & 40,92 & 46,60 & 54,96 \\
\hline
\end{tabular}

Dari Tabel 4 bisa disajikan menjadi grafik perbandingan volume yang hilang pada material yang bisa dilihat pada Gambar 5 .

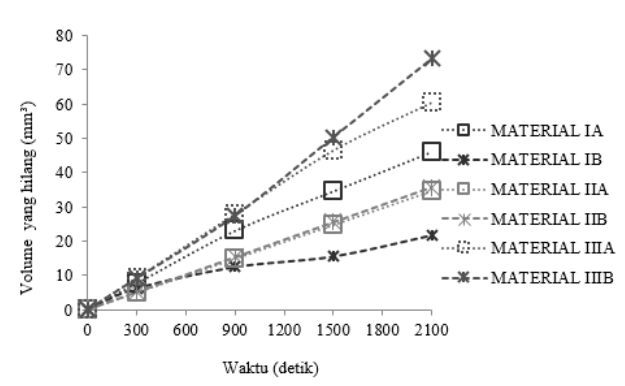

\section{Gambar 5 Volume yang Hilang antar material}

Dari gambar 5 dapat dilihat bahwa volume yang hilang pada tiap material bebeda. Semakin kasar material maka semakin besar pula laju keausan yang dimiliki, begitupun sebaliknya.

\section{Koefeisen Keausan}

Koefisien yang hilang pada material dapat dicari dengan menggunakan persamaan (6) dan hasil eksperimen koefisien yang hilang dapat dilihat pada tabel 5 .

Tabel 5 Koefisein Keausan

\begin{tabular}{ccccccc}
\hline \multirow{2}{*}{$\begin{array}{c}\text { Waktu } \\
\text { (menit) }\end{array}$} & \multicolumn{5}{c}{ Korfisien Keausan (mm²/N) } \\
\cline { 2 - 7 } 5 & Mat IA & Mat IB & Mat IIA & Mat IIB & Mat IIIA & Mat IIIB \\
\cline { 2 - 7 } & $1,3 \cdot 10^{-8}$ & $1,0.10^{-8}$ & $8,1.10^{-9}$ & $8,3 \cdot 10^{-9}$ & $1,5 \cdot 10^{-8}$ & $1,5 \cdot 10^{-8}$ \\
15 & $1,3 \cdot 10^{-8}$ & $6,8 \cdot 10^{-9}$ & $8,1 \cdot 10^{-9}$ & $8,3 \cdot 10^{-9}$ & $1,5 \cdot 10^{-8}$ & $1,5 \cdot 10^{-8}$ \\
25 & $1,2 \cdot 10^{-8}$ & $5,1 \cdot 10^{-9}$ & $8,1.10^{-9}$ & $8,3 \cdot 10^{-9}$ & $1,5 \cdot 10^{-8}$ & $1,6 \cdot 10^{-8}$ \\
35 & $1,1 \cdot 10^{-8}$ & $5,1 \cdot 10^{-9}$ & $8,1.10^{-9}$ & $8,3 \cdot 10^{-9}$ & $1,4 \cdot 10^{-8}$ & $1,7 \cdot 10^{-8}$ \\
\hline
\end{tabular}

Dari tabel 5 bisa disajikan menjadi grafik perbandingan volume yang hilang pada material yang bisa dilihat pada gambar 6 .

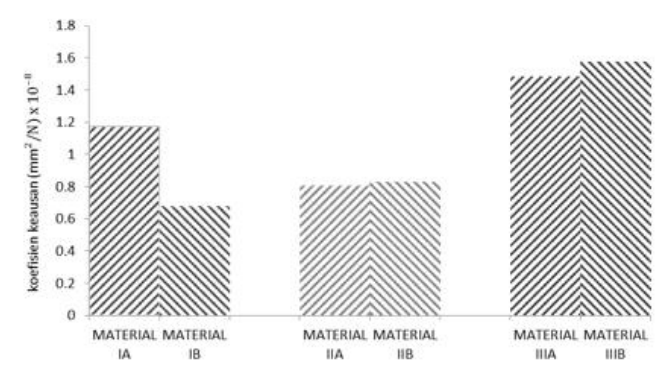

\section{Gambar 6 Grafik perbandingan Koefisien Keausan antar material}

Dari Gambar 6 dapat dilihat bahwa koefisien keausan pada tiap material bebeda. Semakin kasar material maka semakin besar pula koefisien keausan yang dimiliki, begitupun sebaliknya.

\section{Prediksi Umur Kampas}


Untuk mencari prediksi umur kampas dapat dicari menggunakan persamaan (7) dan hasil eksperimen bisa dilihat pada tabel 6 .

Tabel 6 prediksi Umur Kampas

\begin{tabular}{ccccccc}
\hline \multirow{2}{*}{ Waktu } & \multicolumn{2}{c}{ Material I } & \multicolumn{2}{c}{ Material II } & \multicolumn{2}{c}{ Material III } \\
& Sisi A & Sisi B & Sisi A & Sisi B & Sisi A & Sisi B \\
Menit & $2.731,88$ & $1.583,55$ & $2.997,18$ & $2.910,38$ & $1.433,42$ & $2.55,3$ \\
Jam & 45,53 & 26,39 & 49,95 & 48,51 & 23,89 & 42,5 \\
\hline
\end{tabular}

Dari Tabel 6 bisa disajikan menjadi grafik perbandingan volume yang hilang pada material yang bisa dilihat pada gambar 7 .

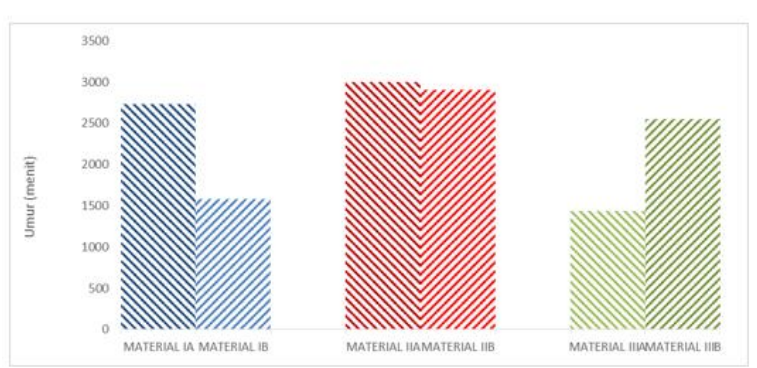

\section{Gambar 7 prediksi umur pakai kampas antar material}

Dari Gambar 7 dapat dilihat bahwa prediksi umur pada tiap material bebeda. Semakin kasar material maka semakin pendek umur pakai yang dimiliki oleh suatu material, begitupun sebaliknya.

\section{KESIMPULAN}

Adapun hasil yang diperoleh penulis dalam penelitian ini adalah sebagai berikut:

1. Nilai laju keausan yang terjadi pada material kampas rem semakin lama cenderung stabil dan mengalami penurunan.

2. Volume yang hilang dan koefisien keausan tertinggi terjadi pada material dengan kandungan asbestos (kampas III) kemudian diikuti oleh material dengan kandungan non-asbestos (kampas II) dan (kampas I).

3. Prediksi umur material paling panjang terjadi pada material dengan kandungan non-asbestos (kampas II) kemudian di ikuti material yang mengandung nonasbestos (kampas I) dan yang cepat habis terjadi pada material yang mengandung asbestos (kampas III).

\section{SARAN}

1. Perlu diperhitungkan sebuah formula yang tepat untuk mempertimbangkan keausan pada disc brake.

2. Perlu dilakukan penelitian lanjutan mengenai material uji guna mendapatkan komposisi yang pas untuk dijadikan material kampas yang lebih baik untuk kedepannya.

\section{DAFTAR PUSTAKA}

Ahmad Multazam, Achmad Zainuri, Sujita, 2012, “Analisa Pengaruh Variasi Merek Kampas Rem Tromol Dan Kecepatan Sepeda Motor Honda Supra X 125 R Terhadap Keausan Kampas Rem", Dinamika Teknik Mesin, Volume 2 No.2 Juli 2012, Jurusan Teknik Mesin, Fakultas Teknik, Universitas Mataram, Mataram

Archard, J. F. (1953). Contact and rubbing of flat surfaces. J. Appl. Phys., 24, 981-988

R.S.khurmi, J.K Gupta 2005, "A textbook of Machine Design". New Dehli : Eurasia Publishing House

Sukamto, Bardi A.J., 2013, “Analisis Perpindahan Panas Kampas Rem Pada Sepeda Motor", Jurnal Teknik, Vol.3 No.1/April 2013, Teknik Mesin Universitas Janabadra, Yogyakarta

Sukamto, 2012, "Analisis Keausan Kampas Rem Pada Sepeda Motor", Jurnal Teknik, Vol.2 No.1 / April 2012, Teknik Mesin Universitas Janabadra, Yogyakarta

Sularso \& Suga K, 2002, Dasar Perencanaan dan Pemilihan Elemen Mesin, edisi kesepuluh, Pradnya Paramita, Jakarta.

Van Vlack L \& Djapri S, 1991, Ilmu Dan Teknologi Bahan (Ilmu Logam dan Non Logam), edisi kelima, Erlangga, Jakarta. 